\title{
Avulsion fracture of the straight and reflected heads of rectus femoris
}

\author{
D. J. DEEHAN*, T. F. BEATTIE*, D. KNIGHT ${ }^{\dagger} \&$ H. \\ JONGSCHAAP ${ }^{\ddagger}$ \\ ${ }^{*}$ Accident $\mathcal{E}$ Emergency Department, ${ }^{\dagger}$ Department of Orthopaedics, and ${ }^{\ddagger}$ Department \\ of Diagnostic Radiology, Aberdeen Royal Infirmary, Foresterhill Road, Aberdeen
}

\section{SUMMARY}

We present a rare case of avulsion fracture of the reflected head of rectus femoris. This occurred in a 13-year-old male footballer. Diagnosis was made with pelvic radiology and treatment was bed rest and analgesia.

\section{INTRODUCTION}

Avulsion fractures are well recognized in adults, as are such injuries in teenage athletes. These are mainly the result of vigorous activity such as running or dancing (Crenshaw, 1987). We present a case report on a young male who sustained an avulsion fracture of the reflected head of rectus femoris which we believe has not been commented upon before, associated with a fracture of the anterior inferior iliac spine.

\section{CASE REPORT}

A 13-year-old boy was playing football and experienced a 'give' in his thigh while kicking a football. Subsequent to this he developed persistent pain localized to his left lateral upper thigh worsened by movement. He was unable to fully weightbear. He reported to the Accident \& Emergency Department of the Aberdeen Royal Infirmary the following day. He had no previous medical history of note.

Correspondence: $M r$ T. F. Beattie, Accident E Emergency Department, Aberdeen Royal Infirmary, Foresterhill Road, Aberdeen AB9 2ZB. 
Upon examination active flexion and passive hyperextension of the left thigh were painful. He was tender over the lateral side of the hip joint. Abduction and adduction were unimpaired. There was no disruption to distal vascular or neurological supply.

Radiological examination of the left hip was performed (Figs 1 \& 2) which revealed an avulsion fracture from the lateralized outer aspect of the acetabulum in conjunction with partial avulsion of the origin of the straight head from the anterior inferior iliac spine. The former lesion was consistent with the anatomical origin of the reflected head of rectus femoris. There was no abnormality detected on the contralateral side. No operative intervention was indicated and he was treated with bed rest for 3 days and simple analgesia. He was then encouraged to mobilize and review after a further 2 weeks revealed that he was asymptomatic and had full painless function present at the hip joint. Review at 3 months indicated no residual problems.

\section{DISCUSSION}

The rectus femoris muscle is made up from two heads which fuse at a short distance to form the main muscle belly. It arises from two heads, the straight head arising from the upper half of the anterior inferior iliac spine. The reflected head arises from a shallow concavity above the acetabulum and is the primary head. This muscle is unique among the components of the quadriceps group in that not only is it an extensor of the knee joint but it also has a stabilizing action on the hip joint and can easily assist in flexing the hip (McMinn, 1990).

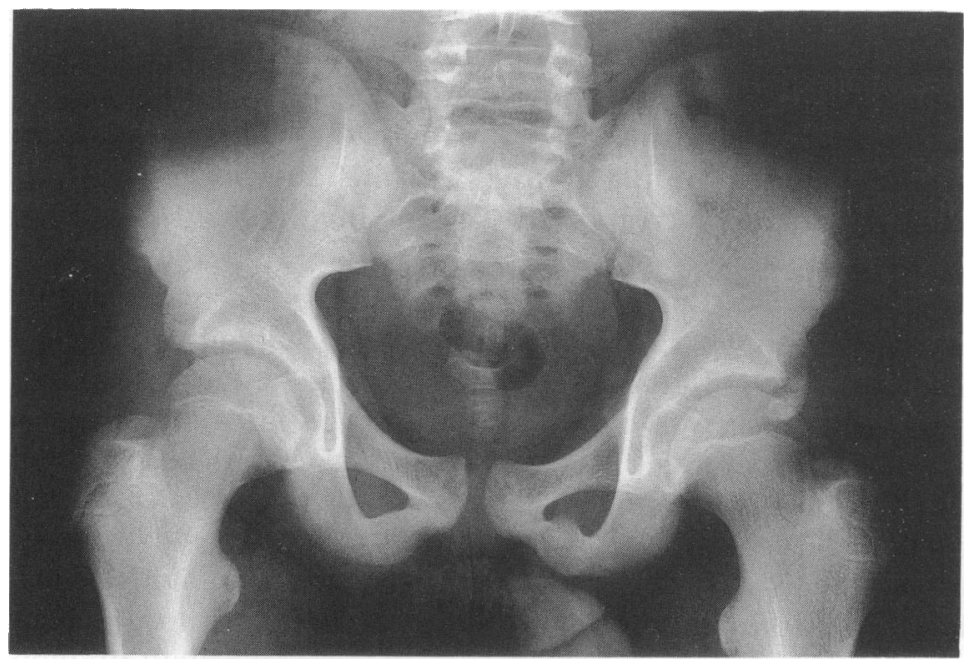

Fig. 1 Antero-posterior view of the pelvis. 


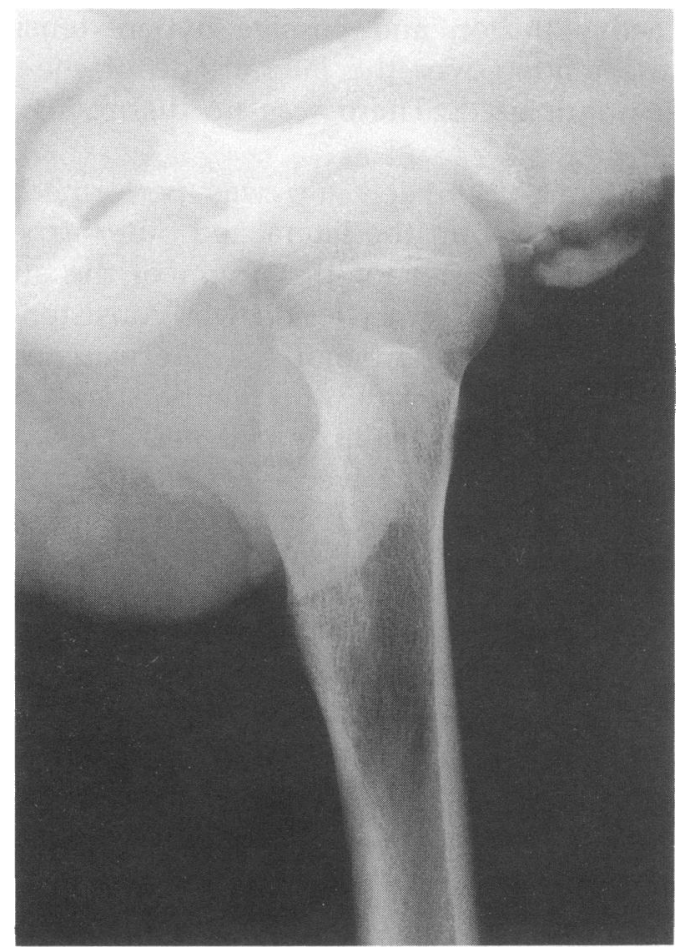

Fig. 2 Lateral view of the pelvis.

Avulsion fracture in adults have previously been classified by Key \& Conwell (1951) into the following categories: (1) involvement of the anterior superior iliac spine; (2) involvement of the anterior inferior iliac spine; and (3) involvement of the ischial tuberosity.

The injury sustained by the young man in our case does not fit clearly into any of these categories. While it involves the anterior inferior iliac spine we believe that this is the first reported case of involvement of the reflected head of rectus femoris.

Avulsion fracture is common in teenage athletes, mainly as the result of vigorous activity such as running or dancing. Weitzner (1985) found them in athletes who kick the ball great distances as in the above case.

Treatment in our case was carried out along the lines of Canale \& King (1984) with no attempt at operative intervention (Kelly, 1963). Bed rest for a few days has previously been recommended with avoidance of physical activity other than swimming for 6-8 weeks.

Exostosis has been described in two cases following avulsion of the anterior inferior iliac spine (Irving, 1964). Our patient has shown no evidence of exostosis development after 3 months, but obviously longer term follow-up would be necessary to exclude this with certainty. 


\section{ACKNOWLEDGEMENTS}

Our thanks to Miss Rebecca Moir for preparing the manuscript and to Medical Illustration for preparing the photographs.

\section{REFERENCES}

Canale S. T. \& King R. E. (1984) Pelvic and hip fractures. In: C. A. Rockwood, K. E. Wilkins \& R. E. King (Eds) Fractures in Children Vol. 3 pp. 740-1. Lippincott, Philadelphia.

Crenshaw A. H. (1987) Campbell's Operative Orthopaedics. Seventh ed. 1987 C.V. Mosby Company, St. Louis.

Irving M. H. (1964) Exostosis formation after traumatic avulsion of the anterior inferior iliac spine report of two cases. Journal of Bone and Joint Surgery 46B, 720-722.

Kelley J. (1963) Ischial epiphysitis. Journal of Bone and Joint Surgery 45A, 435.

Key J. A. \& Conwell H. E. (1951) Management of Fractures; Dislocation and Sprains. C.V. Mosby Company, St. Louis.

McMinn R. M. H. (1990) Last's Anatomy Regional and Applied. 8th ed. pp. 156. Churchill Livingstone, Edinburgh.

Weitzner I. (1935) Fracture of the anterior superior spine of the ilium in one case and anterior inferior in another case. American Medical Journal of Roentgenology 33, 39-40. 